\title{
In vitro Investigation of the Antimicrobial Activity of Mouth Washes Incorporating Zein-Coated Magnesium Oxide Nanoparticles
}

\author{
Ghada H Naguib ${ }^{1,2}$ \\ Gamal S Abd El-Aziz (D) ${ }^{3}$ \\ Hisham A Mously (iD) ${ }^{4}$ \\ Wafaa A Alhazmi iD ${ }^{5}$ \\ Abeer M Alnowaiser ${ }^{6}$ \\ Ali $\mathrm{H} \mathrm{Hassan}^{7}$ \\ Mohamed T Hamed (D) ${ }^{4,8}$ \\ 'Department of Restorative Dentistry, \\ Faculty of Dentistry, King Abdulaziz \\ University, Jeddah, Saudi Arabia; \\ ${ }^{2}$ Department of Oral Biology, Faculty of \\ Dentistry, Cairo University, Cairo, Egypt; \\ ${ }^{3}$ Department of Anatomy, Faculty of \\ Medicine, King Abdulaziz University, \\ Jeddah, Saudi Arabia; ${ }^{4}$ Department of \\ Oral and Maxillofacial Prosthodontics, \\ Faculty of Dentistry, King Abdulaziz \\ University, Jeddah, Saudi Arabia; \\ ${ }^{5}$ Department of Medical Laboratory \\ Sciences, Faculty of Applied Medical \\ Sciences, King Abdulaziz University, \\ Jeddah, Saudi Arabia; ${ }^{6}$ Department of \\ Pediatric Dentistry, Faculty of Dentistry, \\ King Abdulaziz University, Jeddah, Saudi \\ Arabia; ${ }^{7}$ Department of Orthodontics, \\ Faculty of Dentistry, King Abdulaziz \\ University, Jeddah, Saudi Arabia; \\ ${ }^{8}$ Department of Fixed Prosthodontics, \\ Faculty of Dentistry, Cairo University, \\ Cairo, Egypt
}

Correspondence: Mohamed T Hamed Department of Oral and Maxillofacial Prosthodontics, Faculty of Dentistry, King Abdulaziz University, P.O.Box 80209, Jeddah, 21589, Saudi Arabia

Email mthamed@kau.edu.sa
Purpose: This in vitro study was undertaken to investigate the antimicrobial effect of distinctive oral mouth washes after the addition of zein-coated (Magnesium oxide) $\mathrm{MgO}$ nanoparticles on exemplary of some oral microorganisms.

Materials and Methods: Three hundred and twelve samples were used in this study. A set of five concentrations of $\mathrm{MgO}$ nanoparticles with zein and without zein-coating were incorporated into three oral mouth washes: Listerine zero, Listerine total control and Oral $\mathrm{B}$ in the mass percentages of $0.3 \%, 0.5 \%, 1 \%, 2 \%, 5 \%$ and $10 \%$, in addition to controls with no $\mathrm{MgO}$ nanoparticles. The antimicrobial effect of three mouth washes with variable concentrations of $\mathrm{MgO}$ was tested against the following organisms: Staphylococcus aureus, Streptococcus mutans, Enterococcus faecalis and Candida albicans using the disc diffusion test (DDT) and direct contact test (DCT). Data were analyzed using one-way ANOVA statistical test.

Results: The tested mouthwashes with zein-coated $\mathrm{MgO}$ nanoparticles showed significant differences of antimicrobial activity on S. mutans, S. aureus, E. faecalis, and C. albicans in the disc diffusion test. While in the DCT, all tested mouthwashes with $\mathrm{MgO}$ nanoparticles with and without zein coating showed antimicrobial activity on all tested microorganisms.

Conclusion: Zein-coated MgO nanoparticles may be considered as a potential antimicrobial agent when added to oral mouthwashes. Future analysis, including in vivo studies, is required in order to incorporate zein/ $\mathrm{MgO}$ nanoparticles into oral mouthwashes that may improve its antibacterial property.

Keywords: $\mathrm{MgO}$, nanoparticles, zein polymer, antibacterial, mouthwash

\section{Introduction}

Oral diseases such as caries, periodontal inflammation and microbial abscesses are the most common diseases affecting the oral environment. The main causative agents are bacteria, such as Streptococcus mutans, Porphyromonas gingivalis ${ }^{1}$ and fungi as Candida albicans. ${ }^{2}$ Mouthwashes have been used for the prevention of plaque accumulation to decrease the incidence of these diseases. ${ }^{3}$

The metal oxide nanoparticles have been used in medicine for their bactericidal and bacteriostatic properties. ${ }^{4-6}$ These nanoparticles are considered as promising novel antibacterial agents, being harmless to mammalian cells and the oral environment. ${ }^{7}$

As the antibacterial properties of metal ions depend on their surface contact area, the use of nanoparticles leads to increase surface areas and thus increased interaction with organic and inorganic molecules. $\mathrm{ZnO}$ and $\mathrm{TiO}_{2}$ were recently introduced in the 
field of dental materials. They have been added to resin composite restorations for their antibacterial effects. ${ }^{6,89}$ While $\mathrm{Mg}$ is an essential metal to the human body, nanostructured $\mathrm{MgO}$ has been found to be an essential mineral for optimal human health due to its new physical and chemical characteristics. ${ }^{10}$ Nano-MgO was shown to exhibit bactericidal activity directly proportional to particle size and concentration $^{8}$ and to act against both Gram-positive and Gram-negative bacteria. ${ }^{8,9,11,12}$

Many studies have been conducted to assess $\mathrm{MgO}$ nanoparticles due to their properties. ${ }^{9}$ A study done by Makhluf et al, ${ }^{10}$ who synthesized nanocrystalline particles of $\mathrm{MgO}$ using microwave radiation in an ethylene glycol solution, has shown that $\mathrm{MgO}$ has an antibacterial effect on selected bacteria. After testing the antimicrobial effect of nano metal oxides, some researchers demonstrated that nanoparticles of $\mathrm{MgO}$ in solution have a bactericidal effect in opposition to variable bacteria, ${ }^{12}$ In contrast, others proved that $\mathrm{ZnO}$ behaves more than a growth inhibitor especially on Gram-positive organisms. ${ }^{13}$

Also, studies on $\mathrm{MgO}$ nanoparticles' cytotoxicity showed that $\mathrm{MgO}$ nanoparticles were safe when used at concentrations lower than $50 \mu \mathrm{g} . \mathrm{mL}-1 .{ }^{14,15}$

Zein is a natural corn polymer that can be used in the nano form to coat the $\mathrm{MgO}$ nanoparticles in order to prevent their aggregation. ${ }^{16}$ Moreover, it has been reported that it has many unique properties that nominate it to be used in the industry of drug delivery and film coating. ${ }^{17}$ Several investigators believed that zein might serve as an inexpensive and effective alternative to synthetic and semi-synthetic film coatings currently used for extrusion coatings. $^{18,19}$

The addition of antimicrobial agents to mouthwashes and toothpastes preparations inhibited plaque accumulation and bacterial acid production. ${ }^{20}$ Most of the mouth washes normally contain very low concentrations of zinc that showed antimicrobial activity on oral Streptococci. ${ }^{21,22}$ However, the effect of adding $\mathrm{MgO}$ nanoparticles specially coated with zein polymer to the commercial mouthwashes was not studied. Hence, the present study aimed to investigate the antimicrobial effect of the zein-coated $\mathrm{MgO}$ nanoparticles when added to distinctive mouthwashes on an exemplary set of different oral organisms.

While our null hypothesis (Ho) was that the addition of zein-coated $\mathrm{MgO}$ nanoparticles would not make a significant difference to the antimicrobial activity of mouthwashes, the alternative hypothesis $\left(\mathrm{H}_{\mathrm{a}}\right)$ was that it would produce a promising antimicrobial dental product.

\section{Materials and Methods}

$\mathrm{MgO}$ nanoparticles, zein polymer (Sigma Aldrich, Missouri 63103, USA), Listerine Total care mouthwash, Listerine Zero mouthwash (Johnson \& Johnson, New Jersey 08933, USA) and Oral B mouthwash (Procter \& Gamble, Ohio 45202, USA) were used in this study. Agar plates and the sterile paper discs were purchased from Becton, Dickinson and company (New Jersey 07417, USA).

\section{Synthesis of MgO Nanoparticles}

$\mathrm{MgO}$ nanoparticles were synthesized by directly reacting magnesium acetate and urea in the microwave hydrothermal technique as follows: ${ }^{23}$ A solution of $6.44 \mathrm{~g}$ of magnesium acetate in $75 \mathrm{~mL}$ of distilled water was stirred magnetically at $25^{\circ} \mathrm{C}$ for $30 \mathrm{~min}$. Then, drops of a mixture of urea and water $(1.2 \mathrm{~g} / 25 \mathrm{~mL})$ were added under vigorous magnetic stirring for $5 \mathrm{~min}$. An autoclave lined with Teflon was charged with the mixture, secured and kept on a $1000 \mathrm{~W}$ power microwave at $180^{\circ} \mathrm{C}$ for 15 min. After cooling the autoclave and resolution of the reaction, the products were centrifuged for $5 \mathrm{~min}$, filtered with distilled water and then dried at $60^{\circ} \mathrm{C}$ for 24 h. Finally, the white-colored material that resulted was calcinated at $600^{\circ} \mathrm{C}$ for $1 \mathrm{~h}^{23}$

\section{Preparation of $\mathrm{MgO}$-Zein Nanoparticles Using $\mathrm{pH}$-Controlled Nano-Precipitation} The zein polymer was mixed with polyvinyl alcohol (PVA); then $\mathrm{MgO}$ nanoparticles were added at a weight ratio of 4:1. The MgO-zein-PVA mélange was then stirred for 30 minutes. The nanoparticles mix of MgO-zein nanoparticles developed by phase separation. After evaporation of the PVA content, the final product was then centrifuged and dehydrated. ${ }^{24}$

\section{Incorporation of $\mathrm{MgO}$-Zein Nanoparticles in Mouth Wash}

$\mathrm{MgO}$ nanoparticles and zein-coated $\mathrm{MgO}$ nanoparticles were incorporated in three mouthwashes: Listerine Zero, Listerine Total Control (Johnson \& Johnson, NJ 08933) and Oral B (P\&G, Ohio 45202) in the mass percentages of $0.3 \%, 0.5 \% 1 \%, 2 \% 5 \%$ and $10 \%$ based on our previous study, ${ }^{25}$ on the antimicrobial properties of $\mathrm{MgO}$ coated with zein polymer. The solution was kept on a magnetic stirrer at $500 \mathrm{rpm}$ at room temperature for 15 minutes for complete dissolution. 


\section{Antimicrobial Assay}

Two antimicrobial activity tests were carried out: the KirbyBauer agar diffusion test ${ }^{26}$ and the direct contact test. ${ }^{27}$

\section{Cultures of the Microbial Organisms}

The organisms used in the study were acquired from the American Type Culture Collection (ATCC, VA 20110, USA). They are as follows: Streptococcus mutans (ATCC 25175; gram-positive coccus), Staphylococcus aureus (ATCC 25923), Enterococcus faecalis (ATCC 29212) and Candida albicans (ATCC 10231 fungus). The bacteria and fungi concentrations were prepared from stock and cultured on agar and sabouraud agar plates. ${ }^{28}$ All cultures were incubated (Thermo Fischer Scientific, Waltham, MA, USA) at $37^{\circ} \mathrm{C}$.

\section{Determination of Antimicrobial Sensitivity Test of the Mouthwashes Incorporated with $\mathrm{MgO}$ Nanoparticles Disc Diffusion Test (DDT)}

The Kirby-Bauer disc diffusion test ${ }^{26}$ was performed using 156 samples. Freshly prepared inoculums of microorganisms were cultured on blood agar and sabouraud plates. Sterile paper discs of $6 \mathrm{~mm}$ in diameter were filled with $100 \mu \mathrm{L}$ of $\mathrm{MgO}$ nanoparticles or zein-coated $\mathrm{MgO}$ nanoparticles in a solution of different concentrations. Bacteria and fungi were allowed to grow for one day in the $37^{\circ} \mathrm{C}$ incubator, and then inhibition zones were measured. ${ }^{11}$ Antimicrobial inhibition was assessed by measuring the diameter of bacterial inhibition zone $(\mathrm{mm})$, data represents the mean $\pm \mathrm{SD}{ }^{6}$

\section{Direct Contact Test}

The direct contact test ${ }^{27}$ was applied on 156 samples. Freshly prepared inoculums of microorganisms were prepared into a $1 \mathrm{Mc}$ Farland dilution. An equal amount of the bacteria solution and the solution of the different concentrations of $\mathrm{MgO}$ nanoparticles or zein-coated $\mathrm{MgO}$ were mixed. The tubes were incubated at $37^{\circ} \mathrm{C}$. Solutions were then examined for bacterial growth by subculture on fresh media and sabouraud agar plates at different time points: 1 hour and 1, 2, 3, 4, 5, 6 and 7 days.

\section{Plate Count}

Viable bacterial cell concentrations were estimated by counting colony forming units (CFU) before and after exposure to the nanoparticles solutions. This was performed by serial dilution in Broth and then removing $10 \mu \mathrm{L}$ of the serially diluted culture and spreading with sterile glass beads ( $5 \mathrm{~mm}$, Sigma, UK) onto an agar plate (Tryptic Soya Agar) in triplicate. The plates were then incubated at $37^{\circ} \mathrm{C}$ for 24 hours and CFUs were counted. The growth of tested organisms ( $S$. mutans, $S$ aureus, E. faecalis and C. albicans) was observed for the three mouthwashes after 24 hours, 2, 3, 4, 5, 6 and 7 days.

\section{Statistical Analysis}

Data were analyzed using SPSS version 21.0. one-way ANOVA test was performed and the $P$ value less than $0.05(\mathrm{p}<0.05)$ was considered statistically significant.

\section{Results}

Results showed a statistical significant increase in antimicrobial activity against tested organisms when zein-coated $\mathrm{MgO}$ nanoparticles were added to all tested oral mouthwashes rather than non-zein $\mathrm{MgO}$ nanoparticles at $(\mathrm{p}<0.05)$.

\section{The Effect of Tested Mouth Washes on}

\section{S. mutans}

The addition of different concentrations of zein-coated $\mathrm{MgO}$ nanoparticles to Listerine Total care showed a statistical significant increase in the antimicrobial activity against $S$. mutans, $(P=0.0001)$ (Figure 1). A similar effect was noticed with Listerine Zero and Oral B mouth washes. There was a significant difference in the antimicrobial activity against $S$. mutans with the addition of different concentrations of zein-coated $\mathrm{MgO}$ nanoparticles compared to the control and the regular $\mathrm{MgO}$ nanoparticles $(P=0.0001)$ (Table 1, Figure 1).

\section{The Effect of Tested Mouth Washes on}

\section{S. aureus}

All concentrations added of zein-coated $\mathrm{MgO}$ nanoparticles to Listerine Total care showed a statistical significant increase in the antimicrobial activity against $S$. aureus ( $P=0.0001$ ) (Table 1, Figure 2). Furthermore, the addition of all concentrations of zein-coated $\mathrm{MgO}$ nanoparticles to Listerine Zero and Oral B showed a statistically significant increase in the antimicrobial activity against $S$. aureus, rather than the control and the regular $\mathrm{MgO}$ nanoparticles $(P=0.0001)$ (Table 1, Figure 2). 


\section{S. mutans}

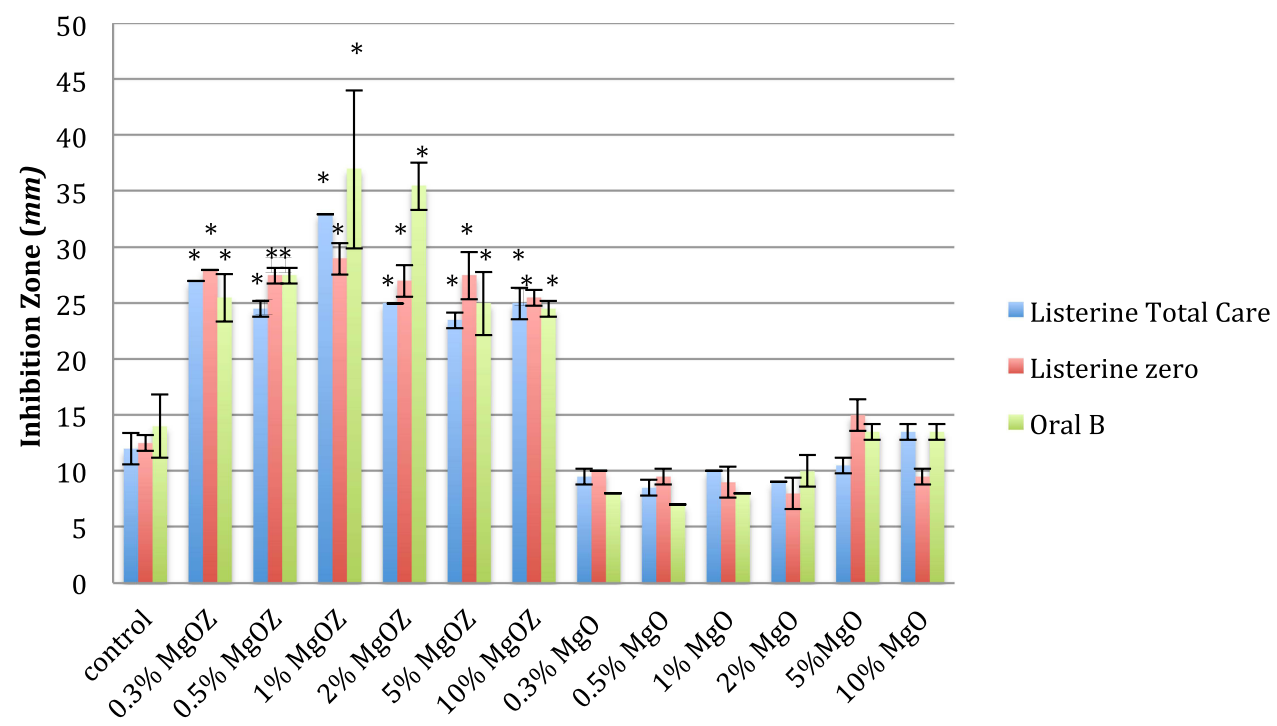

Figure I Diameter of inhibition zones (in $\mathrm{mm}$ ) for Oral B, Listerine Zero and Listerine Total Control with and without zein coated MgO nanoparticles with S. mutans. *Significance at $\mathrm{p}<0.05$.

\section{The Effect of Tested Mouth Washes on E. faecalis}

The antimicrobial effects of all the three mouthwashes: Listerine Total Care, Listerine zero and Oral B after the addition of zein-coated $\mathrm{MgO}$ nanoparticles were statistically significant against $E$. faecalis $(P=0.0001)$ (Table 1, Figure 3).

\section{The Effect of Tested Mouth Washes on}

\section{C. albicans}

The addition of different concentrations of zein-coated $\mathrm{MgO}$ nanoparticles to Oral $\mathrm{B}$ and Listerine Total Care showed a statistically significant increase in the antimicrobial activity against $C$. albicans compared to the control ( $P=0.0001$ ) (Table 1, Figure 4). However, the $5 \%$ and $10 \%$ of zein-coated $\mathrm{MgO}$ nanoparticles added to Listerine Total care showed indifference in the antimicrobial activity between coated and non-coated $\mathrm{MgO}$ nanoparticles.

Meanwhile, there was a statistically significant increase in the antimicrobial activity of Listerine Zero after the addition of $0.3 \%$ and $0.5 \%$ of zein-coated $\mathrm{MgO}$ nanoparticles compared to the control and the $\mathrm{MgO}$ nanoparticles $(P=0.002)$. However, there was no significant difference in the antimicrobial activity between the effect of adding coated or non-coated $\mathrm{MgO}$ nanoparticles in the following concentrations $1 \%, 2 \%, 5 \%$ and $10 \%(p=0.177, p=0.242$, $p=0.242, p=1.00$ ) (Figure 4).

\section{Discussion}

The mouthwashes often contain several antimicrobial agents. They also contain methylparaben (methyl p-hydroxybenzoic acid methyl ester) as a preservative that has an antimicrobial activity. ${ }^{29}$ Listerine mouth washes contain essential oils that may enhance the antimicrobial activity. ${ }^{30}$ However, our in vitro studies showed that the coating of $\mathrm{MgO}$ nanoparticles with zein polymer had no chemical interaction but improved the $\mathrm{MgO}$ nanoparticles stability and prevented their aggregation. ${ }^{24}$ It was also shown that the zein coating by preventing the aggregation of the $\mathrm{MgO}$ nanoparticles enhanced their antimicrobial effect against different oral microorganisms. ${ }^{25}$

Several investigations have added bactericidal agents to oral hygiene products to prevent the plaque accumulation and reduce the bacterial acids. ${ }^{21,31,32}$ Researchers have added copper and zinc in order to enhance the antimicrobial activity of mouthwashes, ${ }^{20,22,33}$ where their studies have reported that mouthwashes with concentration less than $1 \%$ of bactericidal agent can exhibit potential antibacterial effects. ${ }^{22,33}$

In the present study, we added different concentrations of zein-coated and non-coated $\mathrm{MgO}$ nanoparticles to the three most common mouthwashes, in order to examine their potential antimicrobial effect against the most common oral pathogens including S. mutans, S. aureus, E. faecalis and C. albicans. 


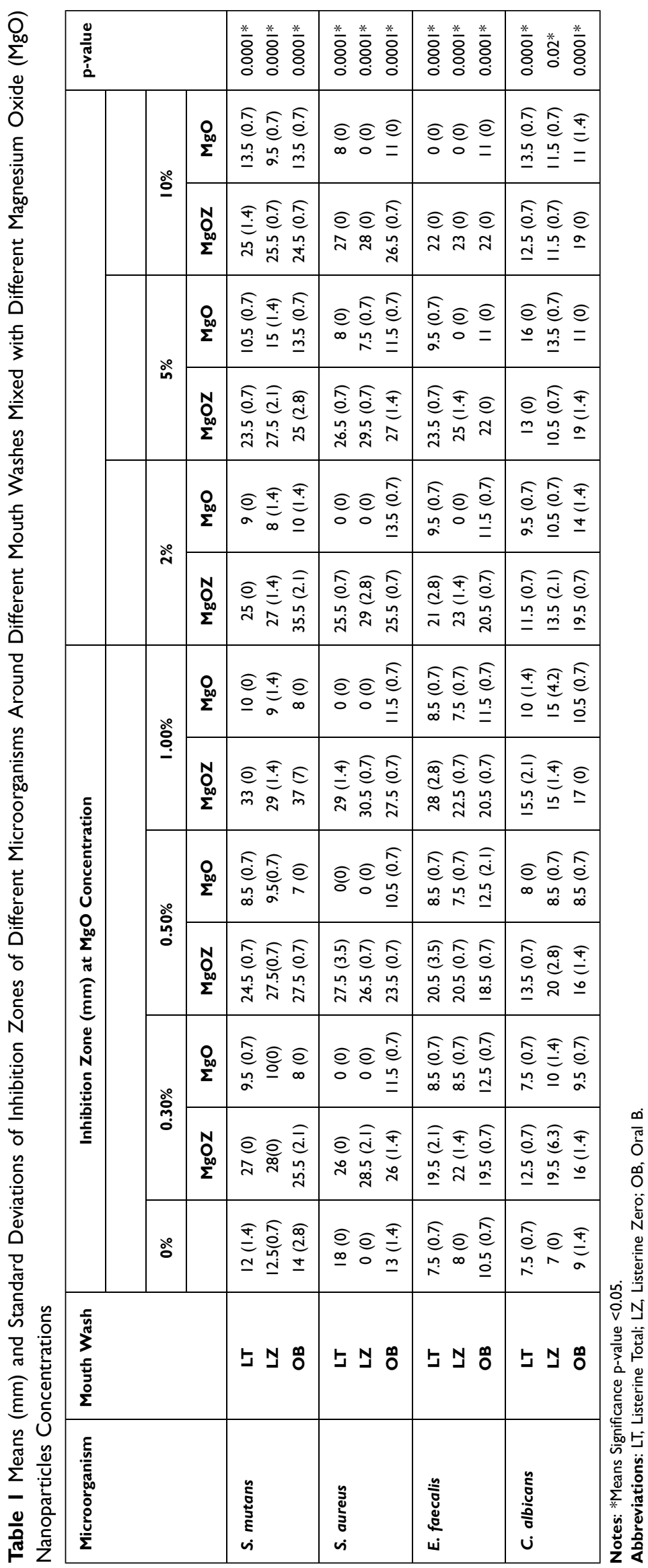




\section{S. aureus}

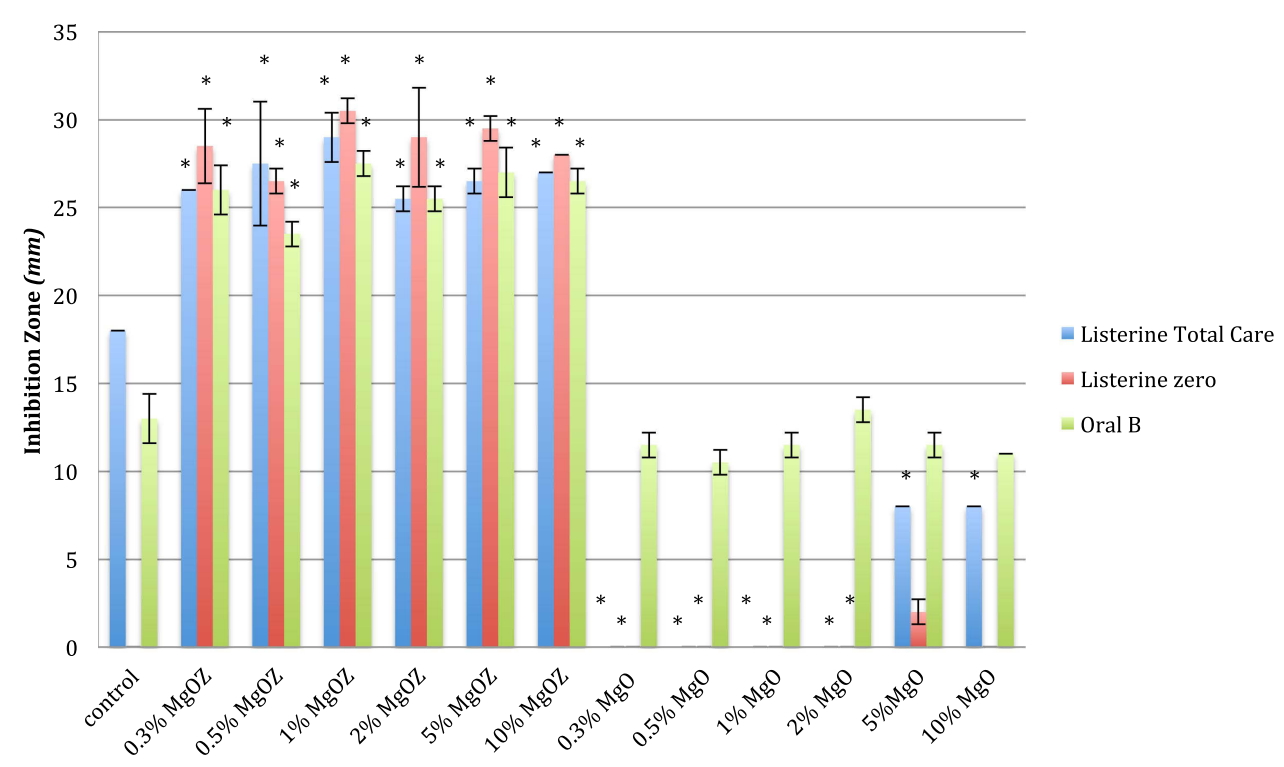

Figure 2 Diameter of inhibition zones (in $\mathrm{mm}$ ) for Oral B, Listerine Zero and Listerine Total Control with and without zein coated MgO nanoparticles with S. aureus. *Significance at $\mathrm{p}<0.05$.

\section{E. faecalis}

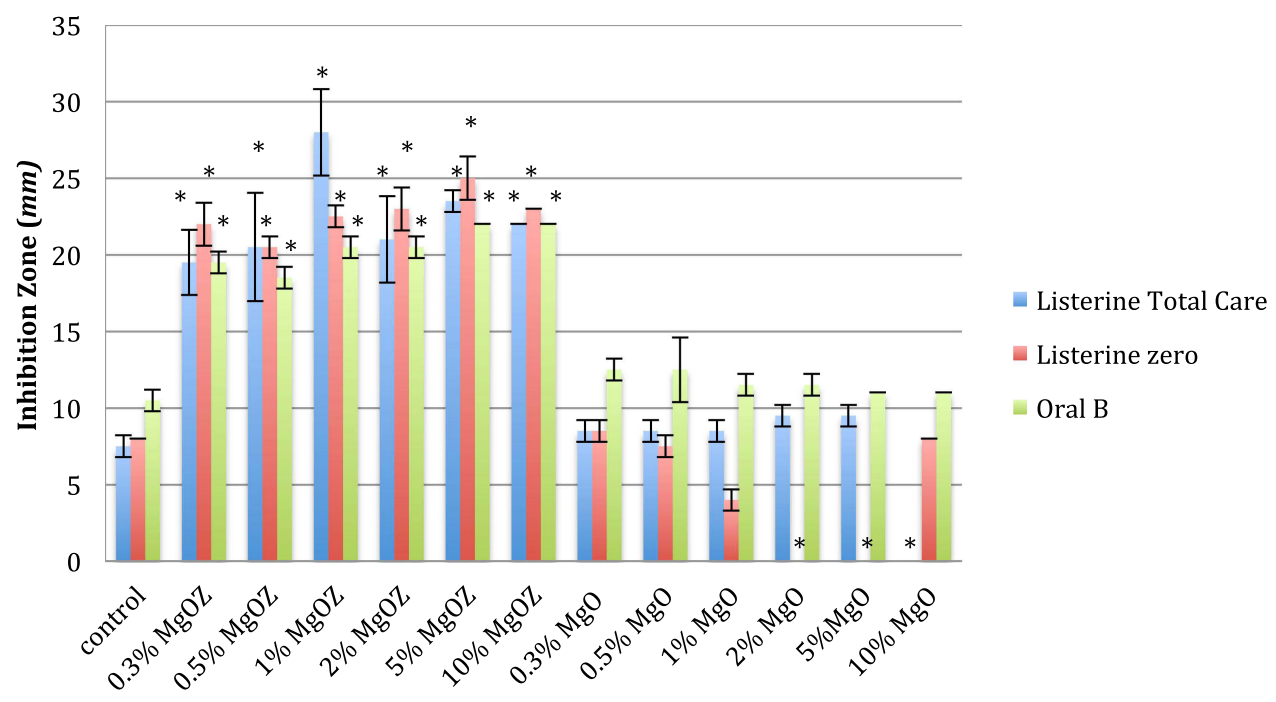

Figure 3 Diameter of inhibition zones (in $\mathrm{mm}$ ) for Oral B, Listerine Zero and Listerine Total Control with and without zein coated MgO nanoparticles with E. faecalis. *Significance at $\mathrm{p}<0.05$.

Interestingly, the overall results showed that incorporating $\mathrm{MgO} /$ zein nanoparticles into the tested mouthwashes could significantly enhance the antimicrobial activity against all tested organisms. Although the $\mathrm{MgO}$ nanoparticles have antimicrobial properties, the preparation of these nanoparticles exhibits aggregation issues that can degrade their properties. Therefore, the use of a surfactant was necessary to help make these particles more soluble. ${ }^{34,35}$
For S. mutans, S. aureus and E. faecalis, all three mouthwashes showed a significant antimicrobial activity results after the addition of $1 \%$ of zein-coated $\mathrm{MgO}$ nanoparticles. These results showed that the addition of zeincoated $\mathrm{MgO}$ nanoparticles had improved the antimicrobial activity of the tested mouthwashes compared to using $\mathrm{MgO}$ without zein. Consequently, the advantage of zein to enhance the antimicrobial activity of the $\mathrm{MgO}$ was 


\section{C.albicans}

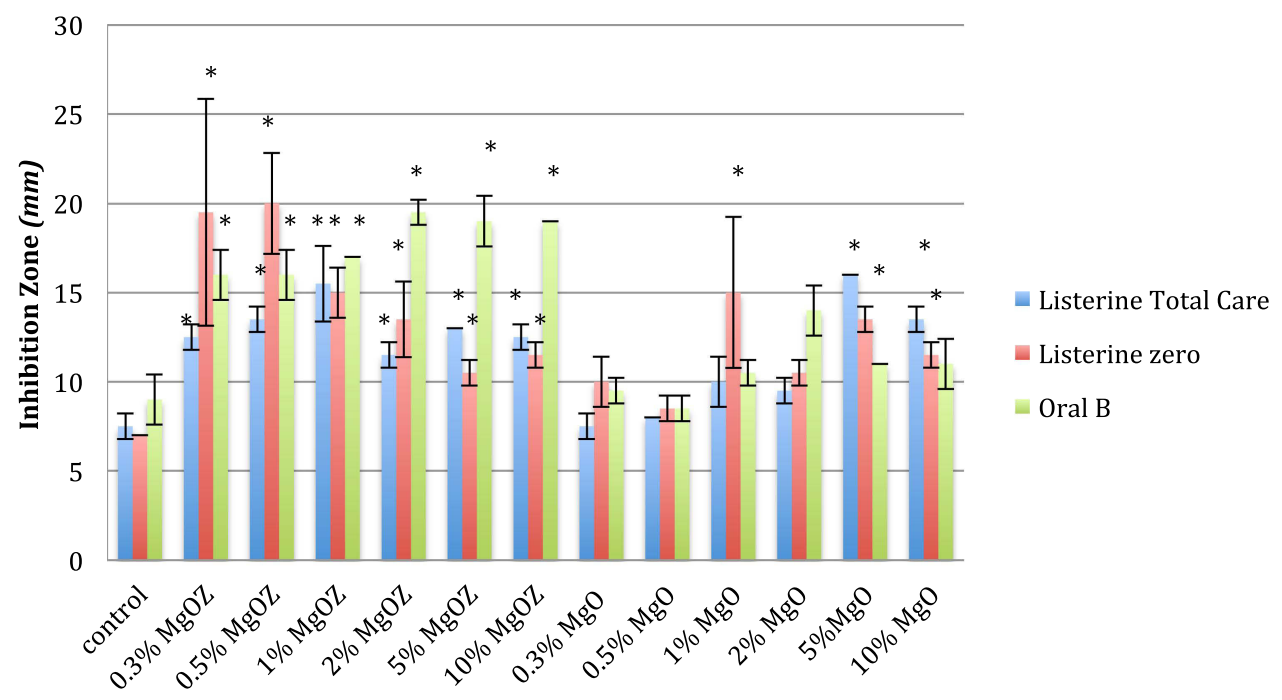

Figure 4 Diameter of inhibition zones (in $\mathrm{mm}$ ) for Oral B, Listerine Zero and Listerine Total Control with and without zein coated MgO nanoparticles with C. albicans. *Significance at $\mathrm{p}<0.05$.

clearly observed. This was in accordance with previous reports that showed the significance of using nanoparticles to improve the antimicrobial activity against certain pathogenic bacteria, suggesting that the use of less than $1 \%$ of bactericidal agent can yield a considerable antimicrobial effect. $^{22,33}$ A similar effect was reported that using $1 \%$ of $\mathrm{Cu}-\mathrm{Ti}$ oxide-treated nanotube coatings has significantly decreased the number of oral bacteria suggesting the efficient antimicrobial effect of nanoparticles. ${ }^{36}$

In this study, various concentrations of $\mathrm{MgO}$ /zein were added to mouthwashes and showed distinct outcomes towards $C$. albicans. The addition of $0.5,1$ and $2 \%$ of $\mathrm{MgO} /$ zein into Listerine zero, Listerine Total care and Oral $\mathrm{B}$, respectively, revealed significant antifungal effects against C. albicans. Similarly, previous studies ${ }^{24,37}$ reported that the use of $0.5-1 \%$ of nanoparticles could considerably decrease the number of oral microbes. It was previously suggested that the inclusion of metal oxides nanoparticles could result in antifungal activity against oral Candidiasis in vitro. Furthermore, several carbon-based nanomaterials, silica, $\mathrm{ZnO}$, and $\mathrm{CuO}$ have been utilized as potential antimicrobial agents for Candida species. For example, small amounts of $\mathrm{ZnO}$ nanoparticles showed an enhanced antimicrobial activity against $C$. albicans due to the damage of fungal cell membrane. ${ }^{38}$ This is in accordance with our results in which using only $0.5 \%$ of zein-coated $\mathrm{MgO}$ nanoparticles has demonstrated a significant antimicrobial effect on C. albicans.
The application of nanoparticles can be quite useful to decrease the rate of microorganisms as well as decrease the chance for the microbes to develop resistance against such molecules. ${ }^{39,40}$ The elevated $\mathrm{pH}$ (alkaline) of $\mathrm{MgO}$ nanoparticles was reported to have a role in their antimicrobial action as this alkaline trait of $\mathrm{MgO}$ may help prevent acidogenic organisms causing dental caries. ${ }^{41}$

The current research was performed to test the benefits of using zein-coated $\mathrm{MgO}$ nanoparticles as antimicrobial agents using simple microbiological methods that are costeffective and available. However, it has been suggested to extend this project to investigate other properties of $\mathrm{MgO}$ nanoparticles, such as anti-biofilm. In addition, one of the limitations of the study is testing the materials against only Gram-positive organisms, and this was due to the difficulties we faced to find and culture Porphyromonas gingivalis, which is known as Gram-negative oral pathogen. Nevertheless, it would be recommended to further examine the effect of zein-coated $\mathrm{MgO}$ nanoparticles towards $P$. gingivalis in future investigation. Another limitation of the current study is being an in-vitro analysis of the antimicrobial effect of zein-coated $\mathrm{MgO}$ nanoparticles. Therefore, further in-vivo studies are required to examine the resulting outcomes of the study.

Overall, the results of this in-vitro study revealed that the addition of zein-coated $\mathrm{MgO}$ nanoparticles to mouthwashes can be effective in improving oral hygiene as it showed a promising antimicrobial activity. However, 
being an in-vitro study can be considered a limitation, as the clinical results of in-vivo studies are still required to confirm the benefits of addition of antimicrobial $\mathrm{MgO} /$ zein nanoparticles. Also, it would be useful to further extend the investigation and examine the effect of these nanoparticles on biofilm infection in the near future to verify the results of this study.

\section{Conclusion}

Within the limitations of this study, zein-coated $\mathrm{MgO}$ nanoparticles have shown a potent antimicrobial activity when incorporated in oral mouth wash products. The zeincoated $\mathrm{MgO}$ nanoparticles can be excellent candidates for further application in the development of oral mouth washes.

\section{Abbreviations}

CFU, colony forming units; DDT, Disc Diffusion Test; DCT, Direct Contact Test; PVA, polyvinyl alcohol; KAU, King Abdulaziz University; ANOVA, analysis of variance; LSD, least significant difference.

\section{Data Sharing Statement}

The datasets used and analyzed during the current study are available from the corresponding author upon reasonable request.

\section{Ethics Approval and Consent to Participate}

The present study has been done and followed by the Ethical Guidelines in the Faculty of Dentistry at King Abdulaziz University (reference number \#094-10-17).

\section{Consent for Publication}

The authors have given their consent for their data to be published in the report.

\section{Author Contributions}

All authors made a significant contribution to the work reported, whether that is in the conception, study design, execution, acquisition of data, analysis and interpretation, or in all these areas; took part in drafting, revising or critically reviewing the article; gave final approval of the version to be published; have agreed on the journal to which the article has been submitted; and agree to be accountable for all aspects of the work.

\section{Disclosure}

The authors certify that they have no affiliation with or involvement in any financial interest (such as honoraria, educational grants, participation in speakers bureau, membership, employment, consultancies, stock ownership, or other equity interest, and expert testimony or patent licensing arrangements) or non-financial interest (such as personal or professional relationships, affiliations, knowledge or beliefs) in the subject matter or materials discussed in this manuscript.

\section{References}

1. Lamont RJ, Koo H, Hajishengallis G. The oral microbiota: dynamic communities and host interactions. Nat Rev Microbiol. 2018;16 (12):745-759. doi:10.1038/s41579-018-0089-x

2. Metwalli KH, Khan SA, Krom BP, Jabra-Rizk MA. Streptococcus mutans, Candida albicans, and the human mouth: a sticky situation. PLoS Pathog. 2013;9(10):e1003616. doi:10.1371/journal. ppat. 1003616

3. Chye RML, Perrotti V, Piattelli A, Iaculli F, Quaranta A. Effectiveness of different commercial chlorhexidine-based mouthwashes after periodontal and implant surgery: a systematic review. Implant Dent. 2019;28:74-85. doi:10.1097/ID.0000000000000854

4. Ivask A, Titma T, Visnapuu M, et al. Toxicity of 11 metal oxide nanoparticles to three mammalian cell types in vitro. Curr Top Med Chem. 2015;15(18):1914-1929. doi:10.2174/1568026615666150506150109

5. Carrouel F, Viennot S, Ottolenghi L, Gaillard C, Bourgeois D. Nanoparticles as anti-microbial, anti-inflammatory, and remineralizing agents in oral care cosmetics: a review of the current situation. Nanomaterials. 2020;10(1):140. doi:10.3390/nano10010140

6. Gordon T, Perlstein B, Houbara O, Felner I, Banin E, Margel S. Synthesis and characterization of zinc/iron oxide composite nanoparticles and their antibacterial properties. Colloids Surf a Physicochem Eng Asp. 2011;374(1-3):1-8. doi:10.1016/j.colsurfa.2010.10.015

7. Sánchez-López E, Esteruelas G, Bonilla L, et al. Metal-based nanoparticles as antimicrobial agents: an overview. Nanomaterials. 2020;10:292.

8. Jin T, He Y. Antibacterial activities of magnesium oxide $(\mathrm{MgO})$ nanoparticles against foodborne pathogens. $J$ Nanopart Res. 2011;13(12):6877-6885. doi:10.1007/s11051-011-0595-5

9. Huang L, Lin D-Q, Lin Y-J, Wei M, Evans DG, Duan X. Controllable preparation of nano-MgO and investigation of its bactericidal properties. J Inorg Biochem. 2005;99(5):986-993. doi:10.1016/j. jinorgbio.2004.12.022

10. Makhluf S, Dror R, Nitzan Y, Abramovich Y, Jelinek R, Gedanken A. Microwave-assisted synthesis of nanocrystalline $\mathrm{MgO}$ and its use as a bacteriocide. Adv Funct Mater. 2005;15(10):1708-1715. doi:10.1002/ adfm. 200500029

11. Gittard SD, Perfect JR, Monteiro-Riviere NA, Wei W, Jin C, Narayan RJ. Assessing the antimicrobial activity of zinc oxide thin films using disk diffusion and biofilm reactor. Appl Surf Sci. 2009;255(11):5806-5811. doi:10.1016/j.apsusc.2009.01.009

12. Shi L-E, Xing L, Hou B, Ge H, Guo X, Tang Z. Inorganic nano mental oxides used as anti-microorganism agents for pathogen control. In: A. Mendez Vilas, editor. Current Research, Technology and Education Topics in Applied Microbiology and Microbial. Formatex, 2010.

13. Vicentini DS, Smania A, Laranjeira MCM. Chitosan/poly (vinyl alcohol) films containing $\mathrm{ZnO}$ nanoparticles and plasticizers. Mater Sci Eng C. 2010;30(4):503-508. doi:10.1016/j. msec.2009.01.026 
14. Lai JC, Lai MB, Jandhyam S, et al. Exposure to titanium dioxide and other metallic oxide nanoparticles induces cytotoxicity on human neural cells and fibroblasts. Int J Nanomedicine. 2008;3(4):533-545.

15. Hasbullah NI, Mazatulikhma MZ, Kamarulzaman N. Nanotoxicity of magnesium oxide on human neuroblastoma SH-SY5Y cell lines. Adv Mater Res. 2013;667:160-164. doi:10.4028/www.scientific.net/ AMR.667.160

16. Podaralla $\mathrm{S}$, Perumal $\mathrm{O}$. Influence of formulation factors on the preparation of zein nanoparticles. AAPS PharmSciTech. 2012;13 (3):919-927. doi:10.1208/s12249-012-9816-1

17. Beck MI, Tomka I, Waysek E. Physico-chemical characterization of zein as a film coating polymer: a direct comparison with ethyl cellulose. Int J Pharm. 1996;141(1-2):137-150. doi:10.1016/03785173(96)04630-3

18. Li X, Guo H, Heinamaki J. Aqueous coating dispersion (pseudolatex) of zein improves formulation of sustained-release tablets containing very water-soluble drug. J Colloid Interface Sci. 2010;345(1):46-53. doi:10.1016/j.jcis.2010.01.029

19. Zhang Y, Cui L, Che X, et al. Zein-based films and their usage for controlled delivery: origin, classes and current landscape. J Control Release. 2015;206:206-219. doi:10.1016/j.jconrel.2015.03.030

20. Phan TN, Buckner T, Sheng J, Baldeck J, Marquis R. Physiologic actions of zinc related to inhibition of acid and alkali production by oral streptococci in suspensions and biofilms. Oral Microbiol Immunol. 2004;19(1):31-38. doi:10.1046/j.0902-0055.2003.00109.x

21. Burguera-Pascu M, Rodríguez-Archilla A, Baca P. Substantivity of zinc salts used as rinsing solutions and their effect on the inhibition of Streptococcus mutans. J Trace Elem Med Biol. 2007;21(2):92-101. doi:10.1016/j.jtemb.2006.12.003

22. Dobl P, Nossek H. The effect of zinc chloride mouthwashes on caries-inducing plaque streptococci. 2. In vivo studies of the antibacterial effect of zinc chloride on the total streptococcal flora of the dental plaque. Zahn Mund Kieferheilkd Zentralbl. 1990;78 (5):393-396.

23. Al-Hazmi F, Alnowaiser F, Al-Ghamdi AA, et al. A new large - scale synthesis of magnesium oxide nanowires: structural and antibacterial properties. Superlattices Microstruct. 2012;52(2):200-209. doi:10.1016/j.spmi.2012.04.013

24. Naguib G, Hassan A, Al-Hazmi F, et al. Zein based magnesium oxide nanowires: effect of anionic charge on size, release and stability. Dig J Nanomater Biostruct. 2017;12(3):741-749.

25. Naguib GH, Hosny KM, Hassan AH, et al. Zein based magnesium oxide nanoparticles: assessment of antimicrobial activity for dental implications. Pak J Pharm Sci. 2018;31:245-250.

26. Maizura M, Fazilah A, Norziah M, Karim A. Antibacterial activity and mechanical properties of partially hydrolyzed sago starch-alginate edible film containing lemongrass oil. J Food Sci. 2007;72(6): C324-C330. doi:10.1111/j.1750-3841.2007.00427.x

27. Slutzkey S, Moses O, Tal H, Meirowitz A, Matalon S. Direct contact test for evaluating bacterial growth on machined and rough surface implants: an: in vitro: study. Implant Dent. 2017;26(6):899-903. doi:10.1097/ID.0000000000000697
28. Lech K, Brent R. Growing bacteria in liquid media. Curr Protoc Cytom. 2001; Appendix 3. doi:10.1002/0471142956.cya03fs 12

29. Agency. EM. Reflection Paper on the Use of Methyl- and Propylparaben as Excipients in Human Medicinal Products for Oral Use.; 2015: 1-13.

30. Alshehri SM, Tiwari RV, Alsulays BB, et al. Investigation of the combined effect of $\mathrm{MgO}$ and PEG on the release profile of mefenamic acid prepared via hot-melt extrusion techniques. Pharm Dev Technol. 2017;22(6):740-753. doi:10.3109/10837450.2016.1138129

31. Lorenz K, Bruhn G, Heumann C, Netuschil L, Brecx M, Hoffmann T. Effect of two new chlorhexidine mouthrinses on the development of dental plaque, gingivitis, and discolouration. A randomized, investigator-blind, placebo-controlled, 3-week experimental gingivitis study. J Clin Periodontol. 2006;33(8):561-567. doi:10.1111/ j.1600-051X.2006.00946.x

32. Petica A, Gavriliu S, Lungu M, Buruntea N, Panzaru C. Colloidal silver solutions with antimicrobial properties. Mater Sci Eng B. 2008;152(1-3):22-27. doi:10.1016/j.mseb.2008.06.021

33. Giertsen E. Effects of mouthrinses with triclosan, zinc ions, copolymer, and sodium lauryl sulphate combined with fluoride on acid formation by dental plaque in vivo. Caries Res. 2004;38 (5):430-435. doi:10.1159/000079623

34. Morsy SM. Role of surfactants in nanotechnology and their applications. Int J Curr Microbiol App Sci. 2014;3(5):237-260.

35. Salager J-L. Surfactants types and uses. In: FIRP Notebook S300- A teaching module in interfacial phenomena, University of Los Andes Venezuela. 2002;2:1-54. www.firp.ula.ve

36. Hang HR, Gao A, Huang X. Antibacterial activity and cytocompatibility of Cu-Ti-O nanotubes. J Biomed Mater Res. 2014;102 (6):1850-1858. doi:10.1002/jbm.a.34847

37. Nabipour YS, Rostamzad A. Comparing the antimicrobial effects of silver and copper nanoparticles against pathogenic and resistant bacteria of Klebsiella pneumonia, Pseudomonas aeruginosa and Staphylococcus aureus. Fen Bilimleri Dergisi. 2015;36 (3):2541-2546.

38. He L, Liu Y, Mustapha A, Lin M. Antifungal activity of zinc oxide nanoparticles against Botrytis cinerea and Penicillium expansum. Microbiol Res. 2011;166(3):207-215.230. doi:10.1016/j. micres.2010.03.003

39. Wang $\mathrm{L}, \mathrm{Hu} \mathrm{C}$, Shao L. The antimicrobial activity of nanoparticles: present situation and prospects for the future. Int $J$ Nanomed. 2017;12:1227-1249. doi:10.2147/IJN.S121956

40. Nakagawa Y, To M, Saruta J, et al. Effect of social isolation stress on saliva BDNF in rat. J Oral Sci. 2019;61(4):516-520. doi:10.2334/ josnusd.18-0409

41. Tang Z-X, Lv B-F. MgO nanoparticles as antibacterial agent: preparation and activity. Braz J Chem Eng. 2014;31(3):591-601. doi:10.1590/0104-6632.20140313s00002813

Clinical, Cosmetic and Investigational Dentistry

Dovepress

\section{Publish your work in this journal}

Clinical, Cosmetic and Investigational Dentistry is an international, peer-reviewed, open access, online journal focusing on the latest clinical and experimental research in dentistry with specific emphasis on cosmetic interventions. Innovative developments in dental materials, techniques and devices that improve outcomes and patien

satisfaction and preference will be highlighted. The manuscript management system is completely online and includes a very quick and fair peer-review system, which is all easy to use. Visit

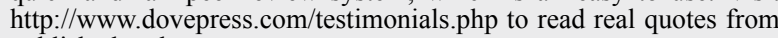
published authors. 